\title{
REPRESENTAÇÕES POPULARES E DE ELITE NA ARGENTINA E NO BRASIL DO ENTRE-GUERRAS A PARTIR DE CARLOS GARDEL E CARMEN MIRANDA
}

\author{
Alessander Mario Kerber \\ Centro Universitário Feevale \\ alekerber@feevale.br \\ Claudia Wasserman \\ UFRGS \\ claudia.wasserman@ufrgs.br>
}

\begin{abstract}
Resumo: Neste artigo, propomos uma análise das representações de identidades populares e de elite, presentes nas músicas, imagem e performance de Carlos Gardel e Carmen Miranda. Parte-se da hipótese de que estes dois artistas foram importantes no processo de negociação e construção das identidades no Brasil e na Argentina, tendo sido os mais famosos intérpretes de seus países, divulgando representações consumidas por um amplo público, numa época de emergência do nacionalismo no entre-guerras e dos meios de comunicação de massas. Em suas músicas, imagem e performance havia representações de identidades populares e de elite que foram associadas às identidades nacionais, sendo, esta associação, o enfoque deste estudo.
\end{abstract}

Palavras-chave: identidades populares e elite; identidade nacional; Carlos Gardel; Carmen Miranda.

\section{Popular and elite representations in Argentina and in Brazil at 1920-1940 from Carlos Gardel and Carmem Miranda}

\begin{abstract}
In the present article, we intend to analyze the popular and elite identities representations into the songs, images and performance of Carlos Gardel and Carmen Miranda. The hypothesis is that those artists were important in the process of negotiation and the Argentinean and Brazilian national identities-building; concerning their performance as interpreters in their countries, and the advertising over their works which were purchased by a large number of consumers in an emergency nationalism between the Wars. In their songs, images and performance, there were also popular representations which were associated with national identity. This association is the theme of study.
\end{abstract}


Key-words: popular and elite identities, national identities, Carlos Gardel and Carmen Miranda.

No contexto histórico do entre-guerras, no Brasil e Argentina, os meios de comunicação de massas, especialmente o rádio e a indústria fonográfica e, através deles, a música popular, tornaram-se elementos que participam na construção de identidades. Especificamente, neste trabalho analisamos a participação das músicas interpretadas por Carlos Gardel e Carmen Miranda neste processo, enfocando a relação estabelecida entre as representações de identidades populares e de elite com as da identidade nacional ${ }^{1}$. Cantores populares de grande sucesso no Brasil e na Argentina, consumidos por grande parte da população, Carlos e Carmem transformaram-se também em representantes da nacionalidade, auxiliando na instauração de um imaginário acerca do Brasil e da Argentina. Na qualidade de ídolos populares, divulgavam idéias, estereótipos e símbolos consumidos por amplos setores da população dos dois países as quais continham, também, representações de identidades populares e de elite que dialogavam com a nação.

O contexto de produção de suas performances artísticas é marcado por um processo de renegociação e redefinição das representações das identidades nacionais ${ }^{2}$. Nessa época, surgiram os primeiros artistas que se tornam ídolos nacionais, tendo suas músicas amplamente difundidas, através dos novos meios massivos de comunicação: o rádio, o cinema e a indústria fonográfica. Quanto à cronologia deste trabalho, considerando que a trajetória artística de Gardel se inicia aproximadamente uma década antes da de Carmen e que a trajetória analisada, no caso de Carmen, estende-se até meia década após a morte de Gardel, constata-se uma diferença que, no entanto, não impossibilita a comparação entre estes casos, devido a existência de similitudes profundas entre as sociedades enfocadas. ${ }^{3}$

Além das diferenças cronológicas entre as trajetórias de Carmem e Gardel, também se observa que na Argentina o desenvolvimento e massificação dos meios de comunicação ocorreram um pouco antes do que no Brasil e que também em relação ao processo de emergência política de segmentos sociais excluídos houve uma certa diferença temporal entre os dois países. Tanto na Argentina, como no Brasil, as elites tradicionais foram levadas a incluírem politicamente segmentos sociais até então excluídos, a partir da vitória eleitoral de Hipólito Yrigoyen, em 1916, e da Revolução de 1930, respectivamente. Esta transformação no Estado tem influência sobre as lutas simbólicas no processo de definição das representações das identidades nacionais. Além disso, a demarcação cronológica, na qual se insere a trajetória artística de Carmen e Gardel, encontra-se dentro do período entre as duas Guerras Mundiais (1918-1939), segundo Hobsbawm, considerado o apogeu dos nacionalismos. 
De modo semelhante, Carmen e Gardel sintetizam em suas canções, imagens, performance e vida pessoal, aspectos da emergência de grupos sociais excluídos e a associação de seus símbolos as identidades nacionais brasileira e argentina. Ambos são artistas que vieram de segmentos populares trazendo algumas das mais significativas representações destes. Assim:

Gardel é um sobrenome argentinizado. Gardel é um imigrante. Ampliando os dados de filiação. Gardel é... um bastardo! Viveu num cortiço, torturado pela pobreza e humilhação. Ali comeu o pão que o diabo amassou, mas também conheceu a solidariedade dos marginais. Era e continua sendo um mistério, porque sua origem manter-se-á sempre cuidadosamente encerrada nas neblinas da especulação. Nesse sentido, ele participa do estigma dos gaúchos, mestiços e quase toda a população dos arrabaldes. Gardel é bastante argentino porque sintetiza muitas das nossas raízes simbólicas. ${ }^{4}$

De forma semelhante, "Carmen era pobre, mas moça de família - e branca. Compunha um arranjo adequado para a República. Antes mesmo de virar estrela circulava pelas duas faces do Rio". 5

$\mathrm{Na}$ construção das identidades nacionais brasileira e argentina, procurouse uma síntese entre identidades distintas. A identidade nacional que se propõe a homogeneizar a sociedade sobrepondo-se sobre as outras identidades, criando um "companheirismo profundo e horizontal"6, também precisa negociar a resignificação das outras formas de identidade dos sujeitos que pretende incluir na nacionalidade. A homogeneização não se dá apenas de forma impositiva, através do Estado; busca-se uma legitimidade nas próprias identidades já existentes. Por exemplo, transformar representações de identidades populares, como o samba e o tango, em representações nacionais, tornou-se uma forma de incluir os até então excluídos à nação, fortalecendo-a.

Uma identidade nacional se forma através de um sentimento e idéia de pertencimento a uma nação, ou seja como representação ${ }^{7}$. Utilizamos o conceito de Anderson, que define que a nação não existe em outra instância senão no imaginário de uma comunidade, sendo imaginada como limitada e soberana. A homogeneização que a identidade nacional propõe conflitua com as diversas identidades existentes no espaço nacional, em especial, com identidades ligadas à condição econômica e à hierarquia social. Optamos por falar em identidades populares e de elite por serem conceitos mais amplos que estabelecem, de forma geral, uma distinção entre identidades de segmentos que ocupam ou não o 'topo' da hierarquia ${ }^{8}$. Como afirma Heinz: "Elite seria um termo empregado em um sentido amplo e descritivo, com referência a categorias ou grupos que parecem ocupar o 'topo' de estruturas de autoridade ou de distribuição de recursos". ${ }^{9}$ 
O contexto das trajetórias artísticas de Carmem e Gardel difere daquele no qual os teóricos europeus se debruçaram para entender a constituição das nacionalidades naquelas regiões. No Brasil e na Argentina dos anos 10 aos 30, diferentemente da Europa do século XIX, existiam eficientes formas de difusão das representações. Referimo-nos especialmente aos meios de comunicação de massa. Estes meios têm uma grande importância no sentido de tornar as representações sobre a nação não mais restritas a um público letrado, mas difundidas massivamente. Assim, as lutas simbólicas em torno da construção da identidade nacional dos dois países tiveram os meios de comunicação de massas, emergentes no Brasil e na Argentina exatamente neste período, como instrumento privilegiado.

No Brasil, as primeiras experiências com rádio datam de 1922, enquanto a massificação data da década de 30 , justamente o período varguista. Na Argentina, esta massificação ocorreu antes, associada ao poder de consumo da sociedade argentina. De acordo com Haussen:

$\mathrm{Na}$ Argentina [...] a indústria de equipamentos radiofônicos desenvolveu-se mais velozmente que a brasileira, bem como o contexto sócio-econômico e cultural era diverso. [...] No final da década de 20, havia no Brasil 19 emissoras em funcionamento enquanto que na Argentina, um país com um número bem menor de habitantes e com uma extensão territorial inferior à brasileira, 36 emissoras já estavam instaladas. E não era só no número que se estabelecia a diferença: esta ocorria também na publicidade, na tecnologia e no conteúdo.

Enquanto no Brasil a programação de cunho educativo e cultural permaneceu por mais tempo, com as emissoras sendo constituídas como radioclubes ou radiosociedades, na Argentina a influência da publicidade começou bem mais cedo. [...] já em dezembro de 1922 surgia a primeira emissora comercial, a "LOX Rádio Cultura", de Buenos Aires. ${ }^{10}$

Conforme Collier, a indústria fonográfica havia se desenvolvido na Argentina desde a década de 1910 e, o rádio, desde 1920:

Las emisoras de radio - las broadcastings, como las llamaban entonces los argentinos - proliferaban en Buenos Aires y las otras ciudades principales: se instalaron más de cincuenta entre 1920 y 1928. Así los horizontes del entretenimiento popular, ya ampliados por el fonógrafo, se ampliaron aun más, en un último hito antes de la era de la televisión. La Argentina estaba convirtiendo en una "sociedad de masas" con sus correspondientes entretenimientos masivos. Era inevitable que el dúo de cantores más famoso del país saliera al aire tarde o temprano. ${ }^{11}$ 
Enquanto na Argentina dos anos 1920 já existia a rádio comercial, no Brasil, a regulamentação para propaganda veio apenas em 1932. Em 1937, havia 63 estações de rádio e 357.921 aparelhos no Brasil, sendo que nos primeiros anos do Estado Novo este número duplicou ${ }^{12}$. Outra nova tecnologia, o gramofone, também auxiliou na difusão e massificação da música. Carmen e Gardel foram os primeiros maiores vendedores de discos do Brasil e da Argentina. Da mesma forma que os aparelhos de rádio, os gramofones também chegaram inicialmente às casas das elites e, no decorrer da década de 30, passaram por um processo de massificação.

Carmen Miranda e Carlos Gardel apresentam-se como mediadores nas negociações sobre as identidades nacionais do Brasil e Argentina, no contexto dos anos 20 e 30. Em suas músicas e imagens traziam representações de grupos excluídos economicamente. Estas representações se relacionaram, de diversas formas, com a identidade nacional. As trajetórias de Carmen Miranda e de Carlos Gardel nos dão indícios importantes para analisarmos como estas identidades eram imaginadas no Brasil e na Argentina e, em especial, como a nação era pensada em relação a elas. As letras das canções interpretadas por ambos nos apresentam, como veremos através de exemplos, a construção imaginária - evidentemente influenciada pela experiência concreta. Por um lado, freqüentemente fala-se no "rico", no "grã-fino", no "bacán", todas expressões associadas a uma identidade que, na falta de uma expressão melhor, chamamos de identidade de elite.

Por outro lado, freqüentemente fala-se no "pobre", na "miseria del arrabal", no "choclo", no "pelele", no "taita", no "caburé", no "malandro", no "mulato", no "negro", no "morocho", no "catra". Todas estas expressões, utilizadas nas canções interpretadas por Carmen ou por Gardel, são representações de outra identidade, uma identidade que não é de elite, uma identidade que pensa sua exclusão das estruturas de autoridade ou de acesso e distribuição de recursos. A expressão genérica de identidades populares é pertinente para identificar os grupos que se pensam como não ocupantes do topo de estruturas de autoridade ou de distribuição de recursos e acesso aos serviços do Estado.

No âmbito da pesquisa não interessa a origem "autêntica" do samba ou do tango, de Carmen Miranda ou de Carlos Gardel, mas que, no contexto em estudo, estes dois estilos musicais, bem como estes dois artistas e uma série de outras representações foram identificados por segmentos da população que eram socialmente excluídos, como representações suas. As carreiras de Carmen e Gardel desenvolveram-se em um período de mudança na percepção da questão social, em ambos os países. Junto à explosão de estrelato de Carmen, aconteceu a Revolução de 30. E, paralelamente à explosão de Gardel, ocorreu a ascensão ao da União Cívica Radical ao poder executivo argentino. Estes fatos marcaram a modificação na organização política, economia e social dos dois países, havendo transformações 
também culturais. No Brasil, a República Velha havia assistido a uma política organizada a partir dos conchavos entre as elites regionais. Os conflitos internos, a quebra da "Política do Café com Leite" e a crise mundial afetaram especialmente os produtores de café de São Paulo, As elites brasileiras, representadas por esses grupos, estava em uma posição muito frágil. Neste cenário ocorreu a emergência política de diversos setores sociais antes excluídos: os setores populares urbanos. Também foi possível o surgimento de um modelo político de apelo popular, especialmente direcionado às massas urbanas, como o que foi implantado por Getúlio Vargas. Este jogo com as camadas populares, porém, não era apenas uma manipulação, mas um processo de acordos com as camadas populares, onde foram feitas concessões a estas. ${ }^{13}$

Tanto pela crise das elites tradicionais, quanto pelo temor desempenhado pela questão social, tendo em vista a Revolução Russa, houve a necessidade de assimilar as camadas populares da população ao jogo político, antes que a sua exclusão resultasse em conflitos incontroláveis. Foi neste sentido que Gomes abordou a questão da pobreza que, durante muito tempo, tinha sido encarada como necessária ao sistema, fornecendo um excedente de mão-de-obra para ser explorada pelos capitalistas. Especialmente após a Revolução Russa, essa condição passou a ser encarada não como uma necessidade do sistema, mas como um perigo para o mesmo. Por isso, surgiu toda uma ideologia acerca da valorização do trabalho e que tentava reduzir a pobreza ao mínimo.

$\mathrm{Na}$ Argentina, diferentemente do Brasil, não houve uma revolução ${ }^{14}$, mas uma contenda eleitoral, em que Hipólito Yrigoyen, da União Cívica Radical, venceu o pleito com $45,6 \%$ do total de $\operatorname{votos}^{15}$. De forma similar ao governo de Vargas, no Brasil, o de Yrigoyen, na Argentina (1916-1922) inaugurou uma nova relação entre Estado e trabalhadores e apelou para uma política de massas, trazendo, para o cenário político, segmentos sociais não pertencentes às elites. Inúmeras vezes o governo interveio nas greves intercedendo em favor dos empregados, desde que os mesmos não se opusessem frontalmente ao modelo agro-exportador. Neste sentido, como no caso brasileiro, percebe-se que, no radicalismo, o Estado não se coloca como representante direto de uma elite, apesar de também não se colocar como representante de uma classe operária, mas sim, um elemento autônomo que negocia com ambos.

Obviamente que o caráter popular no governo Yrigoyen não foi tão explícito quanto no posterior governo Perón. Poder-se-ia afirmar que as condições históricas que proporcionaram o apoio de uma classe operária a Perón não existiam no contexto de Yrigoyen. Porém, isso não impossibilita identificar a emergência de segmentos populares através do representante da UCR. Como afirmam Fausto e Devoto: 
Ao contrário do que ocorreria com Perón, Yrigoyen não conseguiu obter o apoio da classe operária organizada, embora tivesse votos em amplos setores populares. Em seus primeiros anos de governo, realizou uma política de calculada aproximação com os sindicatos e os trabalhadores em geral, na qual se desenhava a inteção de atribuir ao Estado um papel ativo de articulador das relações entre operários e patrões. ${ }^{16}$

Em nível do imaginário político, há uma emergência de grupos populares em oposição às elites. Este processo teve conseqüência sobre a constituição da identidade nacional, pois estes grupos populares tiveram, a partir de então, mais força para impor as suas representações sociais como representações da nacionalidade. Já os discursos iniciais dos mandatos de Yrigoyen e de Vargas tinham uma perspectiva de abrir mais espaço, no estado, para estes segmentos anteriormente excluídos. De acordo com Wasserman, acerca dos discursos:

Os objetos discursivos centrais contidos nos três manifestos [de Vargas, Yrigoyen e Madero] são: a questão da democratização política, as desigualdades regionais, a questão do desenvolvimento econômico e a questão da dependência externa $^{17}(\ldots)$ Operários, setores médios urbanos, camponeses, oligarquias periféricas e descontentes, burguesia industrial incipiente e abandonados em geral pelo sistema, levantaram-se contra as oligarquias ao mesmo tempo em que se apresentava a vulnerabilidade do sitema econômico. Madero, Yrigoyen e Vargas indicavam o caminho da ordem constitucional, da participação política e do sufrágio universal como panacéias para os males da Nação e, assim, passaram a "encarnar a vontade geral", como se fossem os "salvadores da Pátria". [...] Os discursos antioligárquicos de Madero, Vargas e Yrigoyen acabaram funcionando como referências básicas no imaginário constitutivo de seus países. Conhecidos como "apóstolo de la democracia", "pai dos pobres" e "defensor del pueblo", foram responsáveis por discursos e práticas que instauravam um novo sentido à Nação e aos sentimentos de pertencimento. ${ }^{18}$

Ocorre, então, uma renegociação para redefinir as representações da identidade nacional, tanto no Brasil quanto na Argentina. Nesta renegociação são agentes as elites, o Estado (que passava a não ser mais simples defensor dos interesses das elites) e diversos grupos populares e, dentre estes, em especial os que estavam mais próximos do governo e, portanto, mais pressionavam sobre ele, ou seja, os setores populares urbanos, especialmente de Buenos Aires e Rio de Janeiro. Estas negociações tiveram diversos mediadores, como jornalistas, líderes sindicais, burocratas do Estado, intelectuais e artistas e, neste último grupo, destacadamente Carmen Miranda e Carlos Gardel. A oposição entre elites e segmentos populares, 
existente no imaginário das sociedades brasileira e argentina, manifestou-se nas canções interpretadas por Carmen e Gardel e a nação teve de ser pensada dentro deste paradoxo.

No Brasil, anterior a 1930 e, mais ainda, anterior ao modernismo dos anos 20, bem como na Argentina anterior aos governos radicais, as representações predominantes na definição da identidade nacional eram associadas à identidade das elites. No caso brasileiro, em nível simbólico da música, por exemplo, como analisa Contier:

A elite burguesa brasileira de fins do século XIX e início do século XX possuía um forte preconceito em relação às temáticas populares. As músicas oriundas das camadas subalternas ou da população, como, por exemplo, o maxixe, o samba, o entrudo, o choro, eram excluídas da cultura brasileira. ${ }^{19}$

É sobre este tema que muitas canções da época tratavam. Carmen Miranda construiu sua imagem como representante das camadas populares e cantava, geralmente, em defesa destas. No dia 5 de abril de 1939, por exemplo, gravou a canção "Você nasceu p'ra ser granfina", samba de Laurindo de Almeida, que parece representar uma "contra-rejeição" das camadas populares em relação às elites, ou seja, do mesmo modo que estas elites criticavam e desvalorizavam a música popular, a música destas camadas desqualificava as elites:

Você queria aprender o samba mas sua cabecinha não deve andar boa

A sua voz é desclassificada não tem ritmo nem nada, você não entoa

Você nasceu p'ra ser granfina andar na seda e discutir francês

Se compenetre que o samba é alta bossa e é p'ra nêgo de choça que não fala o inglês [...]

Um samba exige tal simplicidade

É justamente o que você não tem

Eu desejava que você soubesse que o samba é a prece do "João Ninguém"

A canção trata de uma distinção entre as elites, na figura da "granfina", e as camadas populares, na figura do "nêgo que não fala inglês". Assim, para a questão da nacionalidade, é interessante notar a relação entre o "granfino" e nacionalidades externas, o inglês e o francês. Nesta música se observa uma clara associação simbólica: se granfino se identificava com inglês, francês, logo, o seu oposto, as camadas populares, se identificariam com o brasileiro. Associação similar encontra-se na canção "Good-Bye", marcha de Assis Valente gravada por Carmen em 1932: 
"Good-bye, good-bye boy", deixa a mania do inglês

Fica tão feio p'ra você, moreno frajola

Que nunca freqüentou as aulas da escola

"Good-bye, good-bye boy", antes que a vida se vá ensinaremos cantando a todo mundo (e com prazer)

b-e-bé, b-i-bi, b-a-bá

Não é mais boa noite, nem bom dia

Só se fala "good-morning, good nigth"

Já se desprezou o lampião de querosene

Lá no morro só se usa a luz da Ligth (oh! Yes)

Nesta canção, Carmen ironiza o "moreno frajola", o representante dos segmentos populares que entra na "mania" de falar em língua estrangeira. Poderíamos identificar nesta música, também uma bipolarização entre o nacional e o estrangeiro: se falar o inglês "fica tão feio" para o moreno frajola, por dedução, sua vocação é falar o português, ou seja, a representação lingüística se vincula à representação popular. Ao mesmo tempo, por outro lado, poderíamos pensar: para quem "não ficaria feio" falar o inglês? A resposta óbvia seria: para os segmentos não-populares, para as elites. Como analisa Garcia, "O uso de palavras estrangeiras confere status ao indivíduo, ao sugerir uma familiaridade com a cultura dita civilizada e, portanto, 'superior' à da maioria dos brasileiros". ${ }^{20}$ Também, esta forma de falar, nesta canção interpretada por Carmen, opõe as elites às representações nacionais.

De forma semelhante, Gardel interpretou uma série de canções que manifestam a oposição entre as elites e os grupos populares, se posicionando, tal como Carmen, como representante das identidades populares. Apresentava em suas canções as representações associadas à identidade de elite como sendo "o outro", a alteridade, a qual era, inclusive, freqüentemente ridicularizada. É o que ocorre, por exemplo, no tango "Carnaval", de Francisco Garcia Jiménez e Anselmo Aieta, gravado por Gardel em 1927:

Sos vos, pebeta. Sos vos ¿Cómo te va?

Estás de baile ¿Con quién?

Con un bacán,

Tan bien vestida, das el golpe,

Te lo digo de verdad.

$[\ldots]$

¿Dónde vas con um mantón de Manila?

¿Dónde vas com tan lindo disfraz?

Nada menos que a un baile lujuoso,

Donde cuesta la entrada um platal.

¡Qué progresos hás hecho, pebeta, 
te cambiaste por seda el percal!

¡Disfarzada de rica estás papa

lo mejor que yo vi em Carnaval! [...]

Nesta canção, Gardel ironiza a moça que, bem vestida, tenta se fazer passar por integrante da elite. Seda e percal são dois tecidos utilizados, respectivamente, como representações da identidade de elite e da identidade popular, e a moça trocou um pelo outro para se disfarçar de rica. Mesmo que Gardel reconheça que a moça está "papa", gíria que, no lunfardo, significa bonita, como disfarçada de rica, a crítica a esta transformação é clara: a moça "deu o golpe" ao conseguir estar com um "bacán", gíria que se refere a um rapaz rico.

Tanto o samba quanto o tango se formaram em meio a segmentos populares e excluídos das sociedades brasileira e argentina. O tango surgiu da mistura de influência de vários grupos étnicos da periferia de Buenos Aires e teve sua forma mais claramente definida em torno da década de 80 do século XIX. Fala-se da influência da milonga, estilo musical criollo argentino, da habanera, estilo trazido pelos espanhóis, além de influências negras, especialmente rítmicas. Este caldeirão de mestiçagem ainda teria sido "enriquecido" pelas diversas influências trazidas pelos vários grupos de imigrantes que chegaram à Argentina entre o final do século XIX e início do XX. A origem de classe do tango é mais precisa do que sua origem étnica. Assim, como afirma Collier: "Su origen social era pobre, marginal, e incluso semidelictivo. Por esta razón fue repudiado largo tiempo por la alta sociedad argentina, aunque los jóvenes sedientos de placer de la classe alta desempeñaron su papel en la propagación del tango por la ciudad." $21 \mathrm{O}$ mesmo autor, ainda, conta que foi no início do século XX que as orquestras de tango chegaram até o centro de Buenos Aires e passaram a ser ouvidas e apreciadas por segmentos das elites e, de lá, lançaram-se para conquistar o mundo.

Assim como o tango surgiu nas orillas de Buenos Aires, o samba surgiu nos morros do Rio de Janeiro. As reformas modernizantes do prefeito Pereira Passos ocorridas no início do século na cidade do Rio de Janeiro haviam expulsado as populações mais pobres do centro. Estas acabaram se acomodando nos morros que cercavam a cidade. Eram os locais próximos às regiões mais centrais, onde freqüentemente tinham de ir para trabalhar e, ao mesmo tempo, distantes o suficiente das elites. O que acontece nos anos 30, no Brasil, e nos anos 10 e 20, na Argentina, é uma vitória simbólica do samba e do tango como estilos musicais que representam ambas as nações, demonstrando, assim, uma vitória dos novos setores populares, especialmente urbanos, que passaram a ter elementos simbólicos para se identificar com a nação.

A oposição e, mesmo, o conflito entre elites e segmentos populares foram, freqüentemente referidos nas canções interpretadas por Carmen e Gardel. Em 
1933, por exemplo, Carmen gravou "Sapateia no chão", samba de Assis Valente, onde aparece esta valorização da cultura popular em relação à das elites:
A Dona Sociedade foi pedir a Pai-de-Santo um remédio que livrasse sua gente dos quebranto
E Pai João lhe receitou um despacho de folia e obrigando todo mundo a batucar de noite e dia

Esta canção parece ter tido origem numa avaliação de Assis Valente sobre o que estava acontecendo politicamente no Brasil. Era o momento em que as elites, representadas pela "Dona Sociedade", se encontravam muito fragilizadas e, obrigadas a fazer concessões às camadas populares para manter a ordem ou, como dizia a canção, as elites foram compelidas a "pedir ajuda ao Pai-de-Santo", símbolo da cultura popular.

A ironia também se apresenta em "Tango, te cambiaron la pinta", tango de Alberto Richard e Juan Benjamín Russo, com letra de Rubén Nicolás "Tabanillo" Fernández, gravado em 20 de junho de 1929. Nesta canção, interpretada por Gardel se ironiza a transformação do tango que, representante dos grupos populares, passou a ser apreciado pelas elites:

Firulete trazao en la vedera
frente al viejo convento de arrabal,
de ande salió la purreta milonguera
que se engrupe a los gilges del Pigall.
Te has llegao hasta el centro 'e prepotencia
y como hombre de agallas te has portao;
y hasta aquellos que la van con decencia
a los sones del fuelle has dominao.
[...]
Te cambiaron la pinta allá en Europa,
y en francés te llamaran "le tangó";
pero vos no has cambiado son la ropa,
y seguís siendo siempre como yo.
El dolor del convento en que naciste,
no sé sei por tau bien o por tu mal,
vas derramando n tu cadencia triste,
como es triste, también, el arrabal...

Outro elemento importante a salientar é que, tanto Carmen quanto Gardel, se apresentavam, nas canções, como identificados com os segmentos populares. Isso pode parecer uma obviedade, pois ambos são cantores oriundos destes segmentos. Porém, nem sempre a origem social dos artistas e a imagem construída por eles e deles coincidem. No caso dos dois cantores, além da origem, ambos construíram uma imagem de si mesmos identificados com os grupos populares. Além da trajetória pessoal, esta questão também se apresenta em outros aspectos de Carmen 
e Gardel como, por exemplo, nos estilos musicais que interpretavam (todos de origem popular) e nas próprias letras das canções. Em 1934, por exemplo, Carmen, gravou o samba "Minha embaixada chegou", de Assis Valente, representação deste conflito entre o morro e a cidade.

Minha embaixada chegou, deixa o meu povo passar

Meu povo pede licença, p'ra na batucada desacatar

[...]

Eu vi o nome da Favela, na luxuosa academia

Mas a Favela p'ro dotô é morada de malandro

que não tem nenhum valor

Não tem doutroes na Favela, mas na Favela tem doutores O professor se chama bamba, medicina lá é macumba cirurgia lá é samba

Já não se ouve a batucada, a serenata não há mais

E o violão deixou o morro e ficou pela cidade

onde o samba não se faz

O próprio título desta canção produz efeitos simbólicos no que se refere à representação dos setores populares. Quando Carmen cantava "Minha embaixada chegou" e se referia ao povo da batucada, ela estava afirmando ser representante das camadas populares da população, ou, tal como um embaixador que representa um país em outro, ela representava as camadas populares do Rio de Janeiro na própria cidade.

Gardel não chegou a utilizar representações oficiais, como a da "embaixada" para salientar ser representante das identidades populares. A utilização da expressão "himno", definindo o tango como um hino do subúrbio no tango "Tango Argentino" (1929), não se referia a ele, mas ao estilo musical.

Porém, mais freqüentemente do que entre as canções interpretadas por Carmen, as de Gardel falavam sobre o sofrimento da população excluída, do subúrbio. E Gardel interpretava as canções com a intimidade de alguém que vivenciara aquela realidade. Ou seja, ao interpretar estas canções, Gardel, mesmo quando não estava falando claramente de si, ele se colocava como integrante daquela realidade social.

Percebe-se um esforço de Gardel, sendo ele mesmo compositor de boa parte das canções que interpretava, em construir esta identidade com segmentos populares. Carmen fez isso através da escolha das canções e ambos fizeram através das imagens e da performance que construíram.

A imagem criada por Gardel colocava-o, em geral, como um representante de algum grupo popular. Como afirma Grünewald, entre os inúmeros personagens que ficaram marcados entre os interpretados por Gardel, temos: 
[...] o boêmio, o gigolô, o guapo, o estudante lírico, o marido enganado, o jogador, o malandro, o trovador, o otário, o bêbado, o filho devotado ou arrependido ou o retratista incessante do comportamento feminino, das mulheres puras e volúveis, líricas ou traidoras, soberbas ou decadentes. E ainda o cantor de Buenos Aires e seus bairros, e mais ruelas, cortiços, cabarés, lampiões, alcovas, hipódromos (1994, p. 38).

Falta, entre os tipos mencionados pelo autor, um que, sem dúvida, foi fundamental, tanto no início da carreira de Gardel quanto em sua trajetória exterior: o "gaucho". A este tipo, também associado a identidades populares, vamos dedicar mais atenção, a qual também daremos à baiana de Carmen.

Outra canção com significativas representações de identidades populares é "Yo se hacer", de autoria do próprio Gardel com Andrés Cepeda, gravada em 1912. Nesta canção Gardel apresenta uma série de signos que remetem a identidades populares. Mais especificamente, remete ao trabalho ligado a estes segmentos, como o saber "una res carnear" ou "capar un potrillo y cuidar un parejero" ou, ainda mais significativo, dado o fato da Argentina ser um país agroexportador, "sé manejar el araopa plantar una semilla" Ele utiliza os verbos "soy" e "sé" para estabelecer esta identificação.

Após estabelecer-se como representante destes segmentos populares do campo, apresenta uma crítica, afirmando que, não tendo estado na escola, será um "gaucho descraciao". Esta crítica poderia ser comparada à apresentada por Carmen em "Cachorro Vagabundo", citada adiante, em que ela, também, fala da exclusão sofrida pelo malandro carioca.

"Yo se hacer" foi uma das primeiras gravações feitas por Gardel, em 1912. Depois, Gardel continuou se identificando com o trabalhador do campo, "gaucho", representante de identidades populares do interior argentino, como o que acontece em uma série de músicas que interpreta principalmente nos primeiros anos, como em "Recuerdos", canção de sua própria autoria com José Razzano, gravada por ele em 1917, ou em "Pavadas", canção de sua autoria com José Razzano, Alberto Novión, gravada em 1919

Em sua história mítica, demonstrada nas letras de suas canções, Gardel parece representar o "gaucho" que vai do campo para a cidade habitar nas "orillas de Buenos Aires". No tango "Flor de Fango", de Augusto Gentile e Pascual Contursi, gravado por Gardel em 1918, ele remete a este espaço de exclusão da cidade de Buenos Aires:

Mina que te manyo de hace rato, perdonáme se te bato de que yo te vi nacer...

Tu cuna due un conventillo alumbrao a querosén.

Justo a los catorce abriles, 
te entregaste a la farra, las delicias de un gotan.

Te gustaban la alhajas los vestidos a la moda y las farras de champan.

Anduviste pelechada, de sirvienta acompañada pa' pasarla e' niña bien, fuiste por muchos envidada porque llevabas buen tren.

Te hiciste chacadora; luego fuiste la señora de un comerciante mishé que lo dejaste arruinado y sin medio, y amurado en la puerta de un café. [...]

Os espaços em que se desenvolve a narrativa desta história são representativos de identidades populares. Entre eles, destaca-se o "conventillo" que, junto aos prostíbulos, como já foi mencionado, são os principais signos espaciais das identidades populares. Os prostíbulos e a vida da prostituição é, talvez, ainda mais do que o espaço do "conventillo" 22 , um tema muito freqüente nas canções interpretadas por Gardel. Em canções como em "Carne de cabaret", tango de Pacífico V. Lambertucci e Luis Roldán, gravado por Gardel em 1920, ou em "Margot", tango de Celedonio Esteben Flores e Josté Ricardo, gravado por Gardel em 1921, o cantor apresenta a pobre vida de uma prostituta com palavras que transmitem a idéia de sua intimidade com o tema, dando a impressão de que ele é alguém que vive neste espaço.

Gardel parece migrar do espaço rural para o espaço urbano, mantendo-se representante dos segmentos populares. As narrativas apresentadas nas letras das canções interpretadas por ele, quando falam de um caminho percorrido, sempre remetem a este trajeto do campo para a cidade ou, então, na cidade, fala-se da saudade do campo. Este caminho seguido do campo para a cidade por segmentos populares também é representado através das mulheres que vêm do interior e acabam na prostituição, em Buenos Aires. É o que se apresenta, por exemplo, no tango "La provinciana", composto por Manuel Romero e Manuel Jovés, gravado por Gardel em 1922:

Era una provincianita, que dejando su casita cayó un día a la ciudad, sin sospechar pobre chica que iba buscando su ruina. $\mathrm{Y}$ bien pronto un compadrito empezó su trabajito con engaño y con maldad. Y la muchacha rodó una noche en el Maipú entre un tango e un foxtrot 
Infeliz provincianita tan gentil y tan bonita, la milonga te apresó, y ya tu vida está marchita, pobre flor, ya está muy lejos el recuerdo de tus viejos, tu candor se disipó y hoy te entregás a la cocó [...]

Gardel, também, se apresenta no lugar de várias figuras populares urbanas, como o vagabundo, na canção "El vagabundo", de sua própria autoria junto a José Razzano, gravada em 1919:

Me llaman el vagabundo porque amanezco en la calle, amanezca o no amanezca, eso no le importa a nadie. [...]

Carmen e Gardel surgiram entre segmentos populares e foram, paulatinamente, sendo apreciados também por setores das elites. Esta apreciação por parte das elites, contudo, parece ter sido maior no caso de Gardel do que de Carmen. No primeiro, parece ter havido quase que um consenso quanto a sua representatividade; Carmem enfrentou freqüentes críticas, havendo uma certa aversão por segmentos das elites, que se manifestou ainda mais fortemente quando de sua turnê nos Estados Unidos. Mesmo assim, Carmem também fez sucesso entre as elites, o que permite presumir que ambos eram representações bem aceitas pelo Estado no contexto em que um "nacionalismo pelo alto" (Hobsbawn, 1990), sofria pressão de um "protonacionalismo popular" e existia uma crise entre as antigas elites que controlavam o Estado. Nesse contexto, Carmen e Gardel se transformaram em ídolos mediadores na renegociação das identidades nacionais.

A utilização de símbolos populares enquanto representantes de toda a nação foi freqüente nas canções interpretadas por Carmen e por Gardel. Por exemplo, em "Se gostares de batuque", que Carmen gravou em 1935, um samba de José Gelsomino (Kid Pêpe):

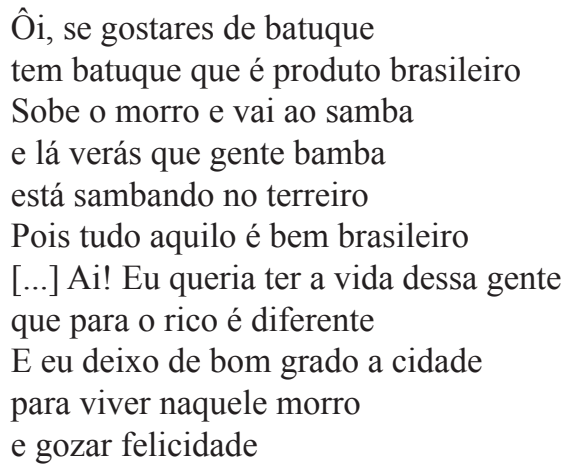

O batuque, oriundo dos morros do Rio de Janeiro, foi apresentado não como representante apenas da cultura popular, mas identificado com o nacional. Ou seja, no momento em que Carmen afirmava que o batuque é produto bem brasileiro, está 
integrando os segmentos que se identificam com ele à nação. Ao mesmo tempo, Carmen valoriza a identidade popular, dizendo que deixa a cidade para viver no morro e gozar a felicidade.

Em 1935, Carmen gravou o grande sucesso "Adeus batucaca", samba de Synval Silva, que foi exaustivamente tocado quando da sua ida para os Estados Unidos e, mais ainda, quando da sua morte. A música não falava em nenhum instante em nação ou em Brasil, mas despertou fortemente o nacionalismo brasileiro. Os segmentos populares parecem que entenderam que, quando Carmen estava dizendo "adeus batucada", que era, originalmente, símbolo da cultura do morro, ela estava, na verdade, dizendo "adeus Brasil". Nisto se mostra a relação de identidade: batucada $=$ Brasil, ou seja, símbolos da cultura de camadas populares representam a nação.

Também no caso argentino, há uma identificação de símbolos da cultura de segmentos populares com a identidade nacional, a qual se manifesta significativamente em canções interpretadas por Gardel como, por exemplo, em "Gacho gris", tango de Carlos Barthe e Alejandro Sami, gravado por ele em 1930:

Gacho gris... compadrito y diquero,

Fiel testigo de un tiempo de farra,

Siempre fuiste mi buen compañero

A quien nunca he podido olvidar.

[...]

Gacho gris, arrabalero

Vos triunfaste, como el tango,

$Y$ escalaste desde el fango

Toda la escala social.

Ayer solo el compadrito

Te levaba requintado,

Pero ahora, funyi claro,

Sos chambergo nacional.

O tango é tomado, nesta canção, como uma personagem com vida própria e que, numa seqüência de triunfos, escalou toda a escala social até que, no presente momento, tornou-se representação nacional. O tango é apresentado, assim, como vitorioso nas lutas simbólicas de representação da identidade nacional e, mais do que isso, como uma vitória dos próprios segmentos sociais que representava.

Em 1936, Carmen gravou "Sambista da Cinelândia", samba de Custódio Mesquita e Mário Lago. Esta canção afirmava que o samba, representante da cultura popular, passava a ser, inegavelmente, "sinfonia nacional", ou seja, fora assimilado pela nacionalidade:

Sambista desce o morro

Vem p'ra Cinelândia, vem sambar 

A cidade já aceita o samba
E na Cinelândia só se vê gente a cantar
Hoje está tudo mudado e acabou-se a oposição
Escolas há por todo lado, de pandeiro e violão
O morro já foi aclamado e com um sucesso colossal
E o samba já foi proclamado sinfonia nacional

Novamente, temos a mesma representação em "Entra no cordão", samba de André Filho, gravado por Carmen em 1936, cuja terceira estrofe fala:
[...] Chora cavaquinho, violão e pandeiro
E canta minha gente que o samba é bem brasileiro [...]

Em 1938, Carmen gravou "Quem condena a batucada", samba de Nelson Petersen. Nele, a associação entre símbolos de identidades populares e nacionais já se apresentava tão configurada no imaginário social que Carmen podia cantar que quem condenava a batucada não era brasileiro:

Quem condena a batucada dessa gente bronzeada
não é brasileiro
E nada mais bonito é que um corpo de mulher
a sambar no terreiro
[...]
Já disseram que o samba nasceu num palácio real
E depois se criou e cresceu em salão multicolor
Mas não sabem que o samba nasceu num cruel barracão
E que foi educado sambando no chão com a gente de cor

No tango "Tango argentino", de Alfredo Bigeschi e Juan Maglio, Gardel apresenta mais claramente a associação entre os símbolos populares e a nação argentina. $\mathrm{O}$ tango, identificado como argentino ou como nacional, apresentava-se como nascido na miséria dos arrabaldes de Buenos Aires. Ao mesmo tempo em que o tango fazia parte da identidade nacional, também era identificado com as classes excluídas economicamente, que passavam, desta forma, a estar incluídas simbolicamente na nação. Gardel gravou "Tango argentino" em 1929, e dizia, sobre este estilo musical:

Es hijo malevo, tristón y canyengue, nació en la miseria del viejo arrabal. Su primer amigo fue un taita de lengue... su mina primera vestía percal...

Recibió el bautismo en una cortada y fue su padrino un taita ladrón.

Se ganó el lado flaco de la muchachada, que en una quebrada le dio el corazón. Tango argentino, sos el himno del suburbio, 
y en jaranas o disturbios siempre supiste tallar. Y que en los patios con querosén alumbrados, los taitas te han proclamado el alma del arrabal...

De tus buenos tiempos aún hoy palpitan El choclo, El Pelele, Taita, El Cabure, La Morocha, El Catra y... La Cumparsita aquel Entrerriano, y el Sábado inglés... Que quieren aquellos jailaifes del centro que te han disfrazado y te han hecho un bacán, serás siempre extraño en su aristrocracia, en cambio sos hijo allá en tu arrabal... Tango argentino, el de cortes compadrones, rezongo de bandoneones y sollozos de violín. Y que en los patios con querosén alumbrados, los taitas te han proclamado el alma del arrabal...

Nesta canção, a associação entre as representações das identidades populares e as representações nacionais é explícita: Gardel afirmava que o tango argentino é um hino do subúrbio. Por transferência de sentido, ele está dizendo que representações nacionais são oriundas das camadas populares. É caso semelhante à utilização, por Carmen, da expressão "embaixada" de "Minha embaixada chegou", uma representação oficial da nação, para representar uma identidade de classe.

Carmen e Gardel também apresentaram críticas contra a ordem social estabelecida. Nestas críticas se percebe mais claramente que estes dois artistas não foram defensores de uma ideologia de Estado, mas que dialogaram com diversos discursos existentes em seu tempo. Em várias canções da década de 30, Gardel retoma esta temática do desespero social, como em "Pan", tango gravado por ele em 1932, com letra de Celedonio Flores e música de Eduardo Pereyra, cuja última estrofe fala:

\author{
¿Trabajar? ¿Adonde? Extender la mano \\ pidiendo al que pasa limosna ¿Por qué? \\ Recibir la afrenta de un "perdone, Hermano"[...]
}

Ou em "Al Mundo le falta un torinillo", tango gravado por Gardel em 1933, com letra de Enrique Cadícamo e música de José María Aguillar, que, em certo momento, fala: 
Y la fuerza se ha hecho gente,

Ya no encuentra a quien robar [...]

Como analisa Collier, pelas letras de suas músicas, acabou sendo, em certa medida, ligada a transgressão:

La presunta delincuencia de Carlos parece pues un mito romántico vinculado con la actitud ambigua de tantas letras de tango - las letras que Carlos iba a cantar - ante los aspectos más sórdidos de la cultura suburbana "marginal" de la qual surgió el tango mismo. ${ }^{23}$

Carmen Miranda não chega a fazer uma exaltação de transgressões como estas. Porém, é freqüente em suas canções, bem como em todo o contexto do samba, a figura do malandro e da malandragem. Esta figura tornou-se um problema no Brasil dos anos 1930, especialmente no Estado Novo. No caso brasileiro, dentro da política de Getúlio Vargas, considerava-se haver alguns entraves culturais que deveriam ser vencidos. Nas músicas interpretadas por Carmen Miranda identificamos o principal deles, sem dúvida, na valorização da malandragem e da vadiagem. A figura do malandro era uma das representações mais significativas de resistência em relação à valorização do trabalho, que se propunha, nos anos 30 . Pior do que isso, esta figura estava intimamente relacionada, no imaginário, ao caráter nacional. É, neste sentido, que Oliven afirma:

Ao voltar da Europa em 1933, Oswald de Andrade teve fina perspicácia ao afirmar que, no Brasil, o contrário do burguês não era o proletário, mas o boêmio. Ironia à parte, ele captou um aspecto essencial da ideologia da cultura brasileira por ocasião do desenvolvimento da industrialização. Assim como no século passado não havia lugar para o exercício de direitos, operando-se, portanto, principalmente com a categoria do favor, no começo do século atual não havia ainda espaço salvo entre militantes anarquistas - para a idéia do conflito entre capital e trabalho, sequer a nível das representações simbólicas. ${ }^{24}$

A valorização da malandragem foi freqüente nos primeiros tempos da carreira de Miranda, como no caso da canção "Cachorro vira-lata", samba-chôro de Alberto Ribeiro, gravado em 4 de maio de 1937, pouco antes do início do Estado Novo, que fazia uma alusão valorativa e muito afetiva em relação à figura do malandro, aí representado, de forma figurativa, pelo cachorro:

Eu gosto muito de cachorro vagabundo que anda sozinho no mundo sem coleira e sem patrão Gosto de cachorro de sarjeta 
que quando escuta a corneta

vai atrás do batalhão

E por falar em cachorro

sei que existe lá no morro um exemplar

que muito embora não sabe

os pés dos malandros lambe

quando eles vão sambar

E quando o samba já está findo

vira-lata está latindo, a soluçar

Saudoso da batucada, fica até de madrugada

cheirando o pó do lugar

E até mesmo entre os caninos

diferentes os destinos costumam ser

Uns tem jantar e almoço

outros nem sequer um osso de lambuja p'ra roer

E quando passa a carrocinha

a gente logo adivinha a conclusão

$\mathrm{O}$ vira-lata coitado que não foi matriculado

desta vez virou sabão

O malandro foi descrito como sendo sem coleira e sem patrão, ou seja, resistente e livre do modelo econômico e social que se tentava adotar no país. Ao mesmo tempo, a canção faz alusão à forte repressão sofrida por ele através da carrocinha, metáfora da polícia que reprime o malandro que "não foi matriculado", ou seja, que não se adaptou ao modelo social.

A política de Vargas visava à construção de um brasileiro que se adaptasse à nova organização do trabalho. Neste sentido, a associação entre brasileiro e trabalhador foi recorrente na propaganda da época. O governo, durante o Estado Novo, passou a intervir diretamente nas letras das músicas populares, censurando as representações que aludiam resistência em relação ao trabalho, como afirma Capelato:

[...] esta fase coincide com o momento em que os ideólogos nacionalistas passaram a se preocupar com a música brasileira no que se referia à música popular. Além do incentivo às letras de exaltação do trabalho, o ambiente político estimulava a criação do samba de exaltação nacional, que teve como melhor exemplo a Aquarela do Brasil de Ary Barroso. Os artistas eram induzidos a compor músicas cujas letras fossem adequadas aos valores apregoados pelo regime e alguns autores foram pressionados a modificar as letras de sambas: as que enalteciam a malandragem tiveram de ser alteradas. ${ }^{25}$ 
E, como explica Napolitano:

[...] foi a partir de um projeto oficial de utilização da música popular para uma pedagogia cívico-nacionalista (sigerido por Lourival Fontes na revista Voz do Rádio, em 1936, e seguido de amplo debate na imprensa) é que a malandragem vai ser combatida "como ponto nodal" do samba, diluindo a figura do malandro no elogio ao trabalhador e à produtividade, na feliz e redundante metáfora do "coqueiro que dá coco". ${ }^{26}$

Para Wisnik, apesar desta tentativa autoritária do Estado Novo em reprimir a representação da malandragem no samba, o vínculo samba/malandragem era tão forte que persistiu, provocando incongruências entre o complexo letra/música. Em seu livro "O roubo da fala", Paranhos analisa diversas formas através das quais os compositores encontraram espaços de liberdade e para burlar, enganar ou, mesmo, ironizar a censura do Estado Novo.

A dificuldade de afirmar a imagem do brasileiro como trabalhador vinha de uma outra construção, mais antiga, que apresentava este brasileiro como avesso ao trabalho. De Jeca Tatu, passando por Macunaíma, até chegar ao malandro carioca, todas estas figuras representam o brasileiro como avesso ao trabalho. No imaginário dos anos 30, apresentam-se, então, duas representações extremamente conflitantes, uma já construída há muito mais tempo, outra proposta pela nova ordem que se estabelecia.

No dia 4 de dezembro de 1929, Carmen gravou o samba "Dona Balbina", no qual se mostra a valorização da folia e da vadiagem e a aversão ao trabalho. Diz a música:

Oh! Dona Balbina, isso assim não pode ser

O trabalho me amofina não nasci para sofrer

Vou me atirar na gandaia

Pois só assim vivo bem

A vida é fogo de palha, meu nêgo

E eu preciso é gostar de alguém, não é

$[\ldots]$

O gosto pela folia, pela orgia e a escolha pela malandragem e pela vadiagem se opõem ao trabalho, que amofina e faz sofrer. Esta representação encontra quase que seu oposto em "Recenseamento", música de Assis Valente, gravada por Carmen no dia 27 de setembro de 1940. Neste momento, auge da censura do DIP, o brasileiro foi representado como trabalhador:

Em 1940 lá no morro começaram o recenseamento

E o agente recenseador esmiuçou a minha vida, foi um horror 
E quando viu a minha mão sem aliança encarou para a criança que no chão dormia

E perguntou se meu moreno era decente e se era do batente ou era da folia

Obediente sou a tudo o que é de lei, fiquei logo sossegada e falei então

O meu moreno é brasileiro, é fuzileiro e é quem sai com a bandeira do seu batalhão

A nossa casa não tem nada de grandeza mas vivemos na pobreza sem dever tostão

Tem um pandeiro, tem cuíca e um tamborim, um reco-reco, um cavaquinho e um violão. [...]

Nesta música, o moreno era o pai de família humilde e honesta, obediente à lei e sossegada para responder às perguntas do funcionário do governo. A grande dúvida era se o companheiro seria malandro ou trabalhador. Isso se manifesta na simbologia utilizada pelo censor ao perguntar se o moreno de Carmen era do batente ou da folia. Carmem, com grande convicção (enfatizada na sua interpretação) respondeu que o seu moreno é "brasileiro, é fuzileiro e é quem sai com a bandeira do seu batalhão". Ela não respondeu se ele era do batente ou da folia, se era trabalhador ou malandro, respondeu que ele era brasileiro e, mais do que isso, militar e nacionalista (representado como aquele que levanta a bandeira e é servidor da pátria). Contudo, com estas palavras, estava dizendo que seu moreno era, sim, um trabalhador, e não um malandro.

Paranhos fez uma análise interessante desta canção, identificando que, apesar do intervencionismo e da censura estatal, houve espaço para que outras versões sobre a nação brasileira fossem construídas, driblando a censura mesmo em seu auge, a partir de 1940, o que mostra a diversidade de agentes envolvidos na negociação sobre esta identidade:

Sem pretender negar a adesão espontânea, forçada ou interessada de muitos compositores populares à cantilena estado-novista, o que se percebe, em dezenas de registros fonográficos do período, é que, apesar dos pesares, o coro dos diferentes jamais deixou de se manifestar, de modo mais ou menos sutil, conforme as circunstâncias. ${ }^{27}$

No período anterior ao Estado Novo, muitas gravações exaltaram a malandragem e a vadiagem. O malandro era uma figura popularmente muito difícil de ser desvalorizada. Havia uma forte magia que envolvia esta figura, a qual era cantada freqüentemente por Carmen, como na canção "Moleque indigesto", gravada em 1933, de Lamartine Babo com a participação especial do mesmo.

Estabelecendo um diálogo com diversos discursos existentes em seu tempo, Carmen Miranda e Calos Gardel se propuseram a representar segmentos 
populares do Brasil e da Argentina e afirmarem representações destes grupos como representações nacionais. Tais representações foram vitoriosas na construção do imaginário acerca destas duas nações. Contudo, mesmo sendo uma vitória simbólica de segmentos populares, temos que levar em conta que não foi, em grande parte dos casos, uma vitória contra as elites, pelo menos a partir do olhar das elites.

\section{REFERÊNCIAS BIBLIOGRÁFICAS}

AGUINIS, M. O atroz encanto de ser argentino. São Paulo: Bei Comunicação, 2002.

ANDERSON, B. Nação e consciência nacional. São Paulo: Ática, 1989.

BACKZO, B. A imaginação social. In: ROMANO, R. (Org.). Enciclopédia Eunaudi. v. 5, Lisboa: Imprensa Nacional, 1985.

BLOCH, M. Pour une histoire compareé des societés européennes. In : MELANGES HISTORIQUES. Paris: Sevpen, 1963.

BURKE, P. A cultura popular na Idade Moderna: Europa, 1500-1800. São Paulo: Cia. das Letras, 1989.

CAPELATO, M. H. R.. Multidões em cena: propaganda política no varguismo e no peronismo. Campinas: Papirus, 1998.

CHARTIER, R. À beira da falésia: a história entre incertezas e inquietude. Porto Alegre: EUFRGS, 2002, p. 73

CHARTIER, R. A história cultural. Lisboa: Bertrand/Difel, 1990.

COLLIER, S. Carlos Gardel - su vida, su música, su época. Buenos Aires:Sudamericana, 1988.

CONTIER, A. D. Brasil novo - música, nação e modernidade: os anos 20 e 30. Tese deLivre Docência em História, Universidade de São Paulo, São Paulo, 1988.

FAUSTO, B., DEVOTO, F. Brasil e Argentina: um ensaio de história comparada (1850-2002). São Paulo: Ed. 34, 2004.

GARCIA, T. C. O “it verde e amarelo” de Carmen Miranda (1930-1946). São Paulo: Annablume; FAPESP, 2004.

GOMES, Â. de C. O populismo e as ciências sociais no Brasil: notas sobre a trajetória de um conceito. In: Tempo, Rio de Janeiro, v. 1, n. 2, p. 31-58, 1996. 
GOMES, Â. de C. Ideologia e trabalho no Estado Novo. In: PANDOLFI, D. (Org.). Repensando o Estado Novo. Rio de Janeiro: FGV, 1999.

GRÜNEWALD, J. L. Carlos Gardel, lunfardo e tango. Rio de Janeiro: Nova Froneteira, 1994.

HAUSSEN, D. F. Rádio e política: tempos de Vargas e Perón. Porto Alegre: EDIPUCRS, 2001.

HEINZ, F. M. Considerações acerca de uma história das elites. Revista Logos, Canoas, v. 11, n. 1, 1988.

HOBSBAWM, E. Nações e nacionalismo desde 1780. Rio de Janeiro: Paz e Terra, 1990.

MARTÍN-BARBERO, J. Dos meios às mediações: comunicação, cultura e hegemonia. Rio de Janeiro: EdUFRJ, 2003.

MENDONÇA, A. R. Carmen Miranda foi a Washington. Rio de Janeiro: Record, 1999.

NAPOLITANO, M. Canção e trabalho no Brasil. In: III SIMPÓSIO NACIONAL DE HISTÓRIA CULTURAL. Florianópolis: UFSC, 2006.

OLIVEN, R. G. Violência e cultura no Brasil. Petrópolis: Vozes, 1989.

PARANHOS, A. O roubo da fala: origens da ideologia do trabalhismo no Brasil. São Paulo: Boitempo Editorial, 1999.

ROMERO, L. A. Breve historia contemporánea de Argentina. Buenos Aires: Fondo de Cultura Económica de Argentina, 1994.

THIESSE, A.-M. Ficções criadoras: as identidades nacionais. Anos 90, Porto Alegre: UFRGS, n. 15, 2001/2002.

WASSERMAN, Cl. Palavra de presidente. Porto Alegre: UFRGS, 2002.

WISNICK, J. M., SQUEFF, E. (Orgs.). O nacional e o popular na cultura brasileira. São Paulo: Brasiliense, 1983. 


\section{NOTAS}

I As fontes utilizadas para esta pesquisa são as canções gravadas por Carmen e Gardel, que são em número de 281 e 930, respectivamente. Também, como fontes secundárias, foram analisados os filmes que contaram com a participação de ambos, os quais oferecem importantes subsídios sobre a performance destes artistas.

2 Cabe, nos casos argentino e brasileiro, a divisão proposta por Hroch para os movimentos nacionalistas. Cf. HOBSBAWM, E. Nações e nacionalismo desde 1780. Rio de Janeiro: Paz e Terra, 1991, p. 2 1. As décadas de 1910 a 1930, na Argentina, e especialmente de 1930, no Brasil seriam, justamente, período de transição entre as fases B e C, em que há a massificação do nacionalismo.

$3 \mathrm{BLOCH}, \mathrm{M}$. Pour une histoire compareé des societés européennes. In : Melanges historiques. Paris: Sevpen, 1963. P. 19.

4 AGUINIS, 2002, p. 75.

5 MENDONÇA, 1999 , p. 42.

6 ANDERSON, 1989, p. 16.

7 Adotamos o conceito de representação como o propõe Chartier. Ao analisar a construção de identidades, Chartier aponta para as perspectivas que a história cultural trouxe a esta questão, diferenciadas de duas visões existentes anteriormente: uma que as via como resultado de imposições de representações e resistências contra estas, outra que as via como exibição de uma unidade construída a partir de um grupo. O autor afirma que "[...] Trabalhando sobre as lutas de representações, cujo objetivo é a ordenação da própria estrutura social, a história cultural afasta-se sem dúvida de uma dependência demasiado estrita em relação a uma história social fadada apenas ao estudo das lutas econômicas, mas também faz retorno útil sobre o social, já que dedica atenção às estratégias simbólicas que determinam posições e relações e que constroem, para cada classe, grupo ou meio, um 'ser-percebido' constitutivo de sua identidade." Cf. CHARTIER, 2002, p. 73.

8 Burke, em Cultura popular da Idade Moderna, analisa o processo de construção da diferença entre uma cultura de elites e uma cultura popular. Nesta análise, propõe, também, uma bipolarização da cultura. Contudo, na introdução à segunda edição do livro, Burke discute a questão do problema conceitual de cultura popular com Roger Chartier. Este último, apontara o problema básico de que a cultura tem limites muito indefinidos. Para ele, não faz sentido identificar cultura popular por alguma distribuição supostamente específica de objetos culturais, como, por exemplo, a literatura de Cordel, pois estes objetos eram usados e apropriados por diferentes grupos sociais, tanto entre elites como entre segmentos populares. Seguindo Bourdieu e Certau, Chartier sugere que o consumo cotidiano é um tipo de produção ou criação, pois envolve as pessoas imprimindo significado ao objeto. Cf. BURKE, 1989, p. 20. Estas considerações propostas por Chartier acerca da definição de uma cultura popular responde, também, à problemática desta pesquisa. Neste sentido, não nos interessa a origem "autêntica" do samba ou do tango, de Carmen Miranda ou de Carlos Gardel, mas que, no contexto em estudo, estes dois estilos musicais, bem como estes dois artistas e uma série de outras representações foram identificados por segmentos da população que se pensavam como excluídas das elites, como representações suas.

9 HEINZ, 1988, p. 50.

10 HAUSSEN, 200I, p. 25.

I I COLLIER, 1988, p. 101

12 CAPELATO, 1998, p. 77.

13 GOMES, 1996, p. 53.

14 Houve uma tentativa revolucionária, em 1905 e, depois, uma certa acomodação, em função da concessão do sufrágio, em 1912 e, finalmente, uma vitória eleitoral, em 1916. 


\section{REVISTA ESBOÇOS N $20-$ UFSC}

I 5 Enquanto que o Partido Conservador (herdeiro do PAN), recebeu 12,86\%, o Partido Democrata Progressista (dissidência conservadora) recebeu 13,23\% e o Partido Socialista, 8,88\%

16 FAUSTO, DEVOTO, 2004, p. 238.

17 WASSERMAN, 2002, p. 38.

18 Idem, pp. 17|-173.

19 Necessário destacar que havia uma diversidade muito grande entre os modernistas dos anos 1920. Apenas uma parte de seu pensamento foi adotado como política de Estado nos anos 1930. Contudo, na maior parte dos modernistas existiu a valorização de manisfestações de signos da identidade popular.

20 GARCIA, 2004, p. 53.

21 COLLIER, 1988, p. 75.

22 Casas pobres e com muitas habitações onde, em geral, residiam os segmentos populares de Buenos Aires. Também, local de aproximação entre os gauchos vindos do interior argentino e os imigrantes extrangeiros, pois freqüentemente habitavam em "conventillos".

23 COLLIER, 1988, p. 28.

24 OLIVEN, 1989, p. $31-32$.

25 CAPELLATO, I998, p. 115.

26 NAPOLITANO, 2006, p. 2.910.

27 PARANHOS, 2002, p. 91. 